\title{
Let's go to the exhibition: extracurricular practice in optoelectronic instrument design course
}

\section{Yao Hu, Qun Hao, Yifan Huang, Ya Zhou}

Yao Hu, Qun Hao, Yifan Huang, Ya Zhou, "Let's go to the exhibition: extracurricular practice in optoelectronic instrument design course," Proc. SPIE 9793, Education and Training in Optics and Photonics: ETOP 2015, 97932I (8 October 2015); doi: 10.1117/12.2223217

SPIE Event: Education and Training in Optics and Photonics: ETOP 2015, 2015, Bordeaux, France 


\title{
Let's go to the exhibition - Extracurricular practice in optoelectronic instrument design course
}

\author{
Yao Hu, Qun Hao*, Yifan Huang and Ya Zhou \\ Beijing Key Lab. for Precision Optoelectronic Measurement Instrument and Technology, \\ School of Optoelectronics, Beijing Institute of Technology, Beijing, China, 100081
}

\begin{abstract}
Principle and Design of Optoelectronic Instruments (PDOI) is a comprehensive engineering course set in the fourth year in School of Optoelectronics, Beijing Institute of Technology, China. After three years of study, the students have acquired basic knowledge in optics, mechanics, electronics, and computer science. They are ready to make a comprehensive application of the knowledge they have learnt in something really important. Like most engineering courses, PDOI needs practical section to help students understand how theories work in engineering. Thanks to the China International Exhibition of Lasers, Optoelectronics and Photonics which is held annually in Beijing, it offers a good opportunity for undergraduates to see advanced instruments with their own eyes. It is a wonderful extracurricular practice for PDOI. In this paper, we will introduce the exhibition-involved curriculum design and give the initial results.
\end{abstract}

Keywords: Engineering course, extracurricular practice, industrial exhibition

\section{INTRODUCTION}

Education can never be limited in classrooms. This is especially true for engineering education of undergraduates. Currently, in China, class-teaching is still the main approach for undergraduates to get professional knowledge. Due to the limited education resource, not all the undergraduates have the chance to take part in research projects or technical competitions like most graduate students do. However, after several years of study in basic theories and skills in certain major, undergraduates with better quality than high-school students, are ready to make something really practical and useful. The career life of further study after graduation also requires engineering experience from practice. Only the knowledge taught in classroom is far from enough. How to find or create meaningful extracurricular activities becomes urgent.

Engineering-related extracurricular activities have been studied by some researchers for the purpose of cultivating innovation capabilities of undergraduate students [1] or attracting new engineering students [2]. Extracurricular activities were also reviewed, and the significance and how to take advantage of these activities as tools for the development and improvement of engineering education within the universities were proposed [3]. Most effective extracurricular activities are well-designed and need considerable manpower and material resources. In China and other countries with large population and limited resources, it is necessary to understand how effective an extracurricular activity can be before pouring significant resources into it.

Industrial exhibitions are held periodically for communications between corporations and potential customers. Exhibitions can be viewed as a good showing stage for new products or techniques, and a platform for communications between people from industry, research institute and universities. From the point of view of an engineering educator, industrial exhibition is also a wonderful classroom for engineering education. It is commonly free, held periodically and highly related to engineering. In this paper, we propose exhibition-involved curriculum design for a comprehensive course given in Senior year in university.

*qhao@bit.edu.cn

Education and Training in Optics and Photonics: ETOP 2015, edited by Eric Cormier, Laurent Sarger Proc. of SPIE Vol. 9793, 97932I · C 2015 SPIE, IEEE, OSA, ICO · doi: 10.1117/12.2223217 


\section{ABOUT PRINCIPLE AND DESIGN OF OPTOELECTRONIC INSTRUMENTS (PDOI)}

\subsection{Introduction to PDOI}

A scientific instrument is often a combination of precision mechanics, optical components, electrical systems and information processing unit like a computer. It is much more than a simple or complex physical principle, but a precise engineering product. The principle and design method for different instruments vary dramatically. However, something in common indeed exists in various instruments. These design criteria are the main content of the course PDOI.

PDOI is a course carried out in the fourth year for all the students in School of Optoelectronics, Beijing Institute of Technology (BIT), China. The main content of the course include basic introduction, accuracy analysis and modern design methods, typical modules (optical sources, elements, and detectors) and typical optical instruments (interferometer, spectrometer, and microscope, etc.). Students are required to master the physical principle, actual structure and main function of several instruments and be able to do simple design. So the teaching sections in the course consist of lectures about the principles and typical examples, several demonstration experiments about classical optical instruments in the classroom, assignments about basic physical principle, measurement data processing, instrument structure and systematical parameter design, and the final examination.

\subsection{Problems due to practice missing}

As discussed above, an optical instrument is a comprehensive precise engineering product. Most people know that a positive lens can form a reduced image, but only those who are majored and experienced in optics, electronics, and mechanics working together can make a practical camera possible. After three years of study, the students in School of Optoelectronics, BIT, have acquired basic knowledge in optics, mechanics, electronics, and computer science. They are ready to make a comprehensive application of the knowledge they have learnt in something really important. Like most engineering courses, PDOI needs practical section to turn students from armchair engineer to a real one. Seeing and using instrument is the basic of analyzing and designing one. Without the practice section, theories in the textbook or on the PowerPoint slides will never turn into experiences and skills of the students. So fast as the modern scientific instruments develop that no textbook or prototype in store can be practical enough. Students will be attractive to novel instruments with advanced technologies because they are too familiar to textbooks and conventional instruments. Only explaining boring principles and equations is not the best way to teach engineering. Extracurricular practice may be a good solution to the urgent problem.

\section{EXHIBITION-INVOLVED CURRICULUM DESIGN}

Instead of designing and constructing a specialized extracurricular activity with manpower and material resources, the more economic and efficient way is bringing the student to a "generalized" classroom, i.e. industrial exhibition.

\subsection{Introduction to the Exhibition}

China International Exhibition of Lasers, Optoelectronics and Photonics is an important exhibition held in October annually in Beijing. It draws the attention of companies, universities, and research institutes in the field of lasers, optics and photonics. Similar with the contents of the PDOI course, the exhibition displays commercial optical parts and instruments from famous companies and also the newest relative technologies from universities and institutes. It is a wonderful extracurricular "example library". Furthermore, development trend in both research and industry can be analyzed from the exhibition. Sometimes, even recruitment information is posted, which directly connects undergraduates and the industry.

\subsection{Curriculum design}

Since the exhibition is available every year at exactly middle of the course, it is set as a special classroom for PDOI. The content of the course and assignment are supplemented with new information from the exhibition.

1) Assignment: visiting the exhibition: The most important and effective section is asking the students to go to the exhibition themselves. They are required to hand in a report describe their visiting. The following questions are compulsory.

- What is the instrument or element that most interests you?

-What is the main principle of the instrument or element? 
- What is the feature that makes the instrument or element special? (Accuracy, novelty, stability or price.)

- What is the price of the instrument or element?

- You are asked to talk with at least three salesmen or technicians. What are the names of them and the corresponding affiliations?

- You are asked to take pictures at the entrance of the exhibition hall and in front of your favorite instrument.

- What is your first impression of the exhibition? Do you think it is helpful for your PDOI study?

Currently the visiting is not compulsory for getting the credit of the course, so an extra bonus directly added to the final score of the course is given as an encouragement as long as the student hands in a qualified report.

2) Special topic: instruments from the exhibition: The teachers also visit the exhibition and bring back the newest information in the form of product catalogue, photos and small tools such as rulers with corporation information on it. New instruments will be added to the content of the course as examples. An interesting setting is that because each student who hands in the visiting report will introduce a kind of instrument in details, when the teacher decides to explain that instrument as an example, the student will be asked to tell his classmate about what he had seen and learnt in the exhibition. The whole class will be much more active if a student is giving the special talk from his own experience.

3) Experience sharing: what I have learnt from the exhibition: Besides professional discussion around the information from the exhibition, a special experience sharing meeting is arranged. About 8 students give presentations about what they had seen in the exhibition and their impression or understanding of the exhibition in front of the class in two hours. The other students can ask questions and post comments.

\section{PRELIMINARY RESULTS}

The exhibition-involved curriculum design has been tried out for three years. Preliminary results are given with some statistic data and students' feedback.

\subsection{Statistic data}

Table 1 shows some statistic data about the course involving exhibition as extracurricular practice. In recent three years, 128 students went to the exhibition to learn more and experience more, taking more than $21 \%$ of the total student number. 10 new instruments have been added to the example library of the course including infrared imaging system, triangulation profiler, image measurement instrument, four-dimensional imaging system, transparent display, et al. Because these instruments are introduced with videos or photos taken by the hand of the students themselves, it is far more interested and convincible than characters on the textbook.

Table 1. Data about the effect of the exhibition

\begin{tabular}{|c|c|c|c|}
\hline Year & Student total number & Number of students visiting exhibition & Number of new instruments added \\
\hline 2011 & 161 & 22 & 3 \\
\hline 2012 & 211 & 65 & 4 \\
\hline 2013 & 235 & 41 & 3 \\
\hline
\end{tabular}

\subsection{Feedback from the students}

Figure 1 shows some of the photos taken in the exhibition. Most of the students who went to the exhibition found it "excited" and "interesting", and only a few were "depressed" because they realized they were too far away from a qualified engineer.

The comments about the exhibition and the course from the students are excerpted and translated as follows. Because the comments about professional problems are not easily understandable to general readers, we only given the feedback concerning engineering course and learning. 

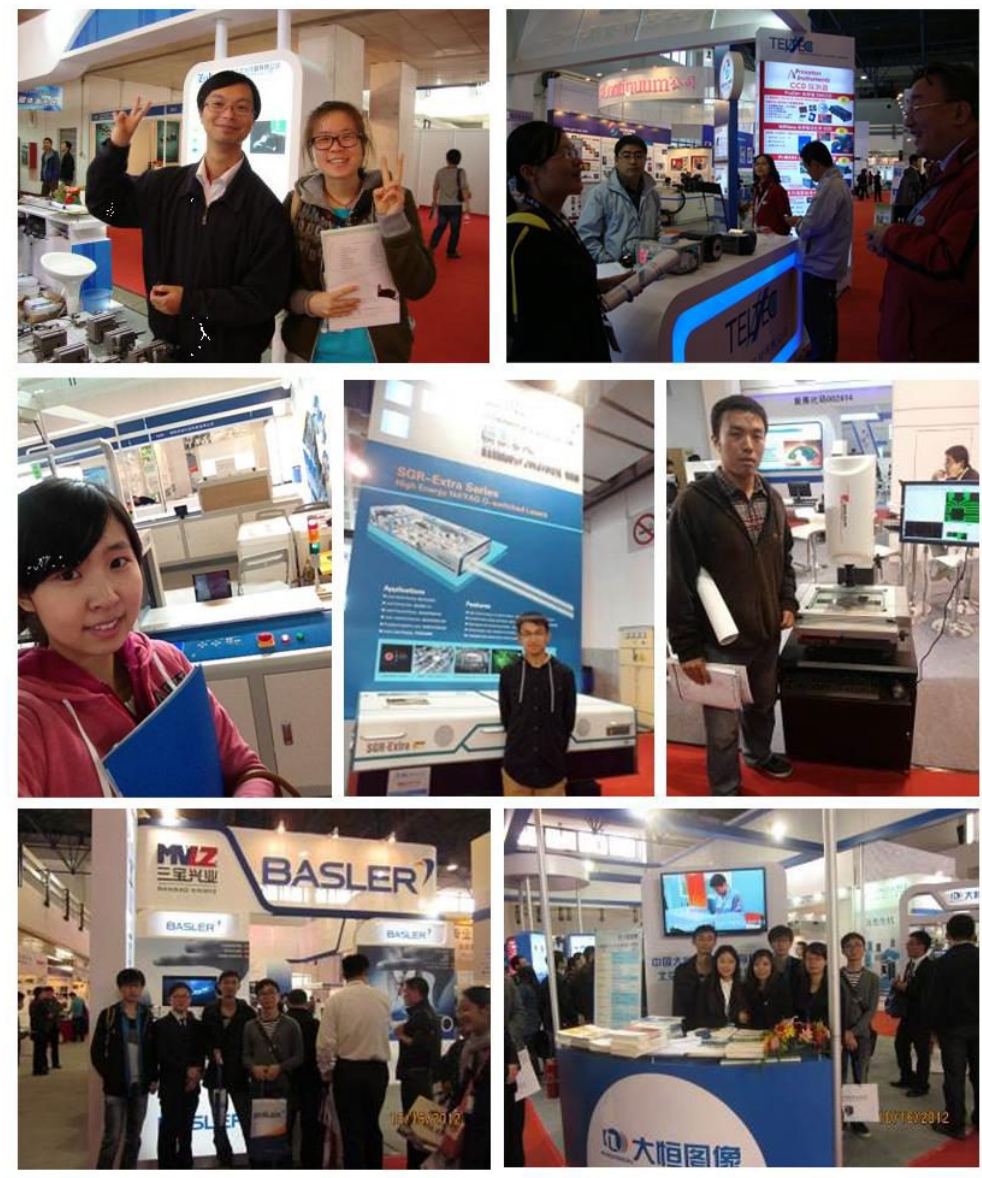

Figure 1. Photos of students taken in the exhibition

- First of all, this is the first time I made personal contact with companies and their respective products related with my major. Each company showed up and sold their latest products in the best form. Secondly, I realized I may get very broad professional employment with my major background. I always thought my major was too professional and limited that it could only be applied to several fields. Sometimes I even doubted whether I could manage related work with the small amount of knowledge we had learned in optoelectronics. After visiting the exhibition, I found that even developing a certain kind of optical devices we learnt in school textbook could support a company. The problem in practical application is much more complex than the principle in the textbook. For example, success in developing a device, the basic principle of which is easy to understand, may need dozens of researchers working hard day and night with innovation. Finally, the most important thing is that visiting the exhibition rekindled my interest and love for the profession. Colorful laser, crystal prisms, lightweight fiber, as well as a variety of high-end smart meter and probe, are no longer boring names but more like familiar friends to me. I am familiar with their principles and application characteristics. This not only made me feel happy to apply the knowledge in application, but also inspired my desire to go further in the major. If I have a similar opportunity in the future, I will go to the exhibition with great interest.

- After visiting the exhibition, I learned something new, although not as much as I thought before, but it really expanded my horizon. With the principles I knew, I could understand some parameters of the instrument, but I could hardly tell the use of many instruments, let alone their parameters or principles. So the first impression after the visiting is that I am still a layman, and according to the teacher's feedback, I am not the only one, maybe many of us feel the same way. 
These are two typical impressions of the exhibition, "interesting" and "depressing". After all, both of them can inspire students to learn more actively and better. The instruments shown in the exhibition do serve as good examples. In the class after the exhibition, students who went to it would consider more about the application and with more open mind. They would think of the similar instrument they had seen in the exhibition. This is a good sign because the exhibition has extended the class to a broader field.

\section{SUMMARY}

Principle and Design of Optoelectronic Instruments is a comprehensive engineering course. Due to the excessive studentteacher-ratio and limited experiment devices, not all the students have the chance to touch and operate a typical optical instrument. Without the practice section, theories in the textbook or on the PowerPoint slides will never turn into experiences and skills of the students. Only explaining boring principles and equations is not the best way to teach engineering. We try to set annual industrial exhibition as the extracurricular practice to help solve the urgent problem. In the first three year tryout, we encouraged the students to visit the exhibition and see real commercial instrument and the industry with their own eyes. We guided them with report assignment and enriched the course content with new instruments in the exhibition. Preliminary results show that the students are more active and interested in the course and have more experiences and open mind in optoelectronic instrument design. In the fall 2014, we will continue setting new tasks concerning the exhibition for the students and make better use of it, especially the technicians in the exhibition.

\section{ACKNOWLEDGEMENTS}

This work was made possible by Beijing Higher Education Young Elite Teacher Project (YETP1171).

\section{REFERENCES}

[1] K. He, X. Liu, and L. Li, "Cultivating innovation capabilities of undergraduate students in extracurricular activities," 6th IEEE Conference on Industrial Electronics and Applications, pp. 1488-1491, 2011.

[2] Juliana Mesquita Vidal Martínez de Lucena, Vicente Ferreira de Lucena Junior, Cláudia Magalhães do Valle, Luiz Henrique Claro Junior, and Antonio da Fonseca de Lira, "Reinventing the engineering: an extracurricular program designed to attract new engineering students," 41st ASEE/IEEE Frontiers in Education Conference, T4D, October, 2011.

[3] Cláudio César Silva de Freitas, Danilo Azevedo Figueiredo, and Yuzo Iano, "Inclusion of Extracurricular Activities and Student Competitions in the Curriculum Structure for Engineering Education: Experience Based on the Brazilian Reality," International Conference on Interactive Collaborative Learning (ICL), pp793-800, September, 2013. 